\title{
The Effect of Influenza Vaccines on Maturation of Dendritic Cells Generated from Bone Marrow
}

Kostinova $\mathrm{AM}^{1 *}$, Yukhacheva $\mathrm{DV}^{2}$, Akhmatova EA $^{3}$, Akhmatova $\mathbf{N K}^{3,4}$, Kostinov $\mathbf{M P}^{3,5}$, Stolpnikova $\mathrm{VN}^{3}$, Bisheva $\mathrm{IA}^{3}$ and Mitrofanova $\mathbf{N N}^{4}$

${ }^{1}$ National Research Center-Institute of Immunology Federal Medical-Biological Agency of Russia, Moscow, Russia

${ }^{2}$ Dmitry Rogachev National Medical Research Center of Pediatric Hematology, Oncology and Immunology Ministry of health of Russia, Moscow, Russia

${ }^{3}$ Federal State Budgetary Scientific Institution «I.I. Mechnikov Research Institute of Vaccines and Sera», Moscow, Russia

${ }^{4}$ Federal State Budgetary Educational Institution of Higher Education «Penza State University» Medical Institute, Penza, Russia

${ }^{5}$ Federal State Autonomous Educational Institution of Higher Education I.M. Sechenov First Moscow State Medical University of the Ministry of Health of the Russian Federation (Sechenov University), Moscow, Russia

*Corresponding author: Kostinova Aristitsa Mikhailovna, National Research Center-Institute of Immunology Federal Medical-Biological Agency of Russia, Moscow, Russia

Received: September 27, 2021; Accepted: October 23, 2021; Published: October 30, 2021

\begin{abstract}
Background: Possibility to control immune system by regulating the activity of Dendritic Cells (DC) with the help of vaccines or other immunobiological drugs opens great prospects for infectious, oncological and autoimmune control. The aim of this study was to evaluate in vitro the effect of adjuvant subunit and non-adjuvant split influenza vaccines on maturation of DCs from human bone marrow.
\end{abstract}

Methods: From bone marrow cells of healthy volunteers, DCs were obtained using rGM-CSF and IL-4. On the 8th day of cultivation, $10 \mu$ l of vaccines against influenza were introduced into the culture of Immature DCs (i-DCs): a non-adjuvant split vaccine (Vaxigripp, Sanofi Pasteur) and an immunoadjuvant subunit vaccine (Grippol plus, Petrovax), as well as immunomodulator Polyoxidonium.

Results: Insertion of influenza vaccines into i-DC culture induced the acquisition by DCs typical morphological signs of maturation. DCs became large with eccentrically located of irregular shape nucleus, densified cytoplasm, numerous processes. By immunophenotypic examination decrease in monocyte/macrophage pool, cells with expression of CD34 immaturity marker, increase in expressing CD11C/CD86 costimulatory molecules and CD83 terminal differentiation molecules were observed. Although Polyoxidonium caused a decrease in number of CD11c/CD14 cells $(18,5 \%)$, but compared to vaccines, its activity was lower $(p<0,05)$. Grippol plus more actively induced differentiation of TLR2 and TLR8 expressing cells, whereas Vaxigripp-expression of TLR4 and TLR8 on DCs.

Conclusion: The possibility of using in vitro model of DCs obtained from human bone marrow cells by cytokine stimulation for examination of the ability of influenza vaccines to induce DC maturation processes has been demonstrated.

Keywords: Dendritic cells; Maturation; Morphology; Immunophenotype; Influenza vaccines

\section{Abbreviations}

DC: Dendritic Cells; FCS: Fetal Calf Serum; i-DC: Immature Dendritic Cells; PBS: Phosphate-Buffered Saline; PO: Polyoxidonium; RBC: Red Blood Cell Lysis Buffer; rGM-CSF: Recombinant Granulocyte-Macrophage Colony-Stimulating Factor; rmIL-4: Recombinant Murine Interleukin-4; TLR: Toll-Like Receptor.

\section{Introduction}

Dendritic Cells (DCs) are the most potent specialized antigenpresenting cells in the body. They initiate immune responses due to their ability to activate naive T-cells [1]. DCs also play an important role in antitumor and post-vaccination immunity, as they can stimulate antigen-specific immune response. DCs can be cultured in vitro and then in immuno-therapy in vivo, and they can also be amplified in vivo using immunobiological drugs-inductors of cytokines or other factors such as Flt-3 [2,3].

DC-based antitumor vaccines as an approach to immunotherapy have attracted much attention in biomedical research and are recognized as one of the most promising approaches for targeted antitumor therapy [4-9].

However, studies aimed at the ability to control the immune system by managing the activation of DCs with the help of vaccines or other immunobiological drugs are also important [10-12]. Of no less importance is the interest in studying the mechanisms of action of various vaccines on the immune response effectors, including innate immunity, and the possibility of activating DCs with their subsequent maturation.

DCs are dispensated throughout the body, accounting for less than $1 \%$ of peripheral leukocytes in animals and humans. In order to obtain a sufficient amount of DCs for research in this work, mononuclear cells of healthy volunteers were isolated from the bone marrow and their differentiation in DCs was induced in vitro using cytokines. Subsequently, DCs were activated by various influenza vaccines, evaluating the processes of subsequent stages of differentiation, up to the terminal phenotypically manifested increase in expression of the surface CD83 molecule [13].

This technology can help to understand the mechanisms of action of various drugs on the immune system. We investigated morphology
Austin J Vaccines \& Immunother - Volume 5 Issue 1 - 2021

Submit your Manuscript | www.austinpublishinggroup.com

Kostinova et al. (C) All rights are reserved
Citation: Kostinova AM, Yukhacheva DV, Akhmatova EA, Akhmatova NK, Kostinov MP, Stolpnikova VN, et al. The Effect of Influenza Vaccines on Maturation of Dendritic Cells Generated from Bone Marrow. Austin J Vaccines \& Immunother. 2021; 5(1): 1012. 
and immunophenotype of the DCs. This study can be the basis for further studies of antitumor vaccines and drugs aimed at activating of innate immunity, as well as provide a model for assessing the immunogenicity of vaccines and other immunobiological drugs.

The aim of the study was to evaluate in vitro the effect of adjuvant subunit and non-adjuvant split influenza vaccines on the maturation of dendritic cells generated from human bone marrow.

\section{Materials and Methods}

\section{Volunteer group characteristics}

In the single-center, open-label, non-randomized study, participated 5 healthy volunteers - 3 men and 2 women (18-40 years old) without concomitant pathology; they have never been vaccinated against influenza and had not have the symptoms of influenza during last 6 months before.

\section{Legal framework of the study}

After signing the informed consent for participation in the study, according to the protocol No.3, approved by the ethics committee in Dmitry Rogachev National Medical Research Center of Pediatric Hematology, Oncology and Immunology and I.I. Mechnikov Research Institute for Vaccines and Sera in 2018, bone marrow was taken from volunteers in compliance with the rules of asepsis and antiseptics. The study was conducted in an accredited laboratory of the I.I. Mechnikov Research Institute for Vaccines and Sera (Moscow) using modern reagents and equipment.

\section{Studied influenza vaccines}

Vaxigrip (Sanofi Pasteur, France) is a trivalent inactivated split influenza vaccine containing $15 \mu \mathrm{g}$ of hemagglutinin of two type A subtypes $(\mathrm{A} / \mathrm{H} 1 \mathrm{~N} 1$ and $\mathrm{A} / \mathrm{H} 3 \mathrm{~N} 2)$ and $15 \mu \mathrm{g}$ of type B (Victoria lineage) influenza viruses.

Grippol plus (NPO Petrovax Pharm LLC, Russia) is a trivalent inactivated subunit influenza vaccine containing $5 \mu \mathrm{g}$ of hemagglutinin of two type A subtypes (A/H1N1 and A/H3N2) and $5 \mu \mathrm{g}$ of type B (Victoria lineage) influenza viruses and also $500 \mu \mathrm{g}$ of the immunoadjuvant Polyoxidonium (Azoximer bromide).

All vaccines contained actual influenza virus strains of the season 2019-2020:

- A / Brisbane / 02/2018 (H1N1) pdm09-like virus;

- A / Kansas / 14/2017 (H3N2) -like virus;

- B / Colorado / 06/2017-like virus (lineage B / Victoria / 2/87);

\section{Characteristics of the adjuvant used in the vaccine}

According its chemical structure, Polyoxidonium (PO) is the copolymer of $\mathrm{N}$-oxide of 1, 4-ethylene piperazine and (N-carboxymethyl)-1, 4-ethylene piperazinium bromide with molecular mass about $80 \mathrm{kDa}$ (INN: Azoximer bromide). This high molecular compound is analogue of natural wide-spread physiologically active $\mathrm{N}$-oxide polymers having strong physiological and pharmacological properties including immune tropic potency.

PO possesses expressed immune modulating effects acting first of all on autarcesis factors such as monocytic-macrophagal system cells, neutrophils and NK-cells and inducing them activation under initially reduced functions. Flow cytochemistry data showed that PO does interact with three lymphocyte subclasses, predominantly binds with monocytes and neutrophils and to a lesser extent with lymphocytes, enhancing intracellular $\mathrm{H}_{2} \mathrm{O}_{2}$ production. Hydrogen peroxide being the secondary messenger activates the transcriptional NF-kB factor that is the participant of the cytokines synthesis regulation. The enhancement of the pro-inflammatory cytokines IL-1 $\beta$, IL-6, TNF- $\alpha$ synthesis takes place. Activation by PO cells of monocyticmacrophagal cluster and natural killers promotes mobilization of both cellular and humoral immunity. Finally all immunity starts up for adequate response development similarly to that as it occurs in natural way [14].

Besides its own clinical application as independent drug, Polyoxidonium is used as immunoadjuvant in new generation vaccines and is a compound in subunit adjuvanted Grippol family vaccines since 1997 when first Grippol' vaccine was registered in Russian market. Due to Polyoxidonium, all Grippol family vaccines contain 3-times lower antigen content in one immunizing dose - 5 mcg per strain, in comparison to $15 \mathrm{mcg}$ per strain in other subunit and split influenza vaccines. This provides Grippol family vaccines with higher safety profile [15-27]. These recommendations were made based on relevant clinical trials results followed by many years practical mass vaccine application experience [28-29]. PO is registered in Russian Federation, CIS countries, Slovakia, Cuba.

\section{DC cultivation}

DCs were obtained from bone marrow cells of 5 healthy volunteers. Bone marrow was homogenized in RPMI-1640 (Sigma, USA), sedimented three times by centrifugation $(250 \mathrm{~g} \times 5 \mathrm{~min})$, then the cell pellet was resuspended using Tris- $\mathrm{NH} 4 \mathrm{Cl}$ Red Blood Cell Lysis Buffer (RBC) and the cells were pelleted again and washed with RBS. Then the cells were transferred to an enriched culturing medium (106cells in 1ml of RPMI-1640 medium supplemented with $10 \mu \mathrm{g} /$ $\mathrm{ml}$ gentamicin sulfate (AppliChem, Germany) and 10\% thermally inactivated fetal calf serum - FCS (Thermo Fisher Scientific, USA) containing $20 \mathrm{ng} / \mathrm{ml}$ each of the recombinant GM-CSF and IL-4 (Biosource, USA).

After 12 hours the medium was changed to remove loose cells and cell debris. On the 8 -th day $10 \mu \mathrm{l} / \mathrm{ml}$ of influenza vaccines were added to the Immature-DC (i-DC) culture. Polyoxidonium was added at the rate of $10 \mu \mathrm{g} / \mathrm{ml}$ of culture medium. Commercial TNF- $\alpha(20 \mathrm{ng} / \mathrm{ml}$, Biosource, USA) was used as a classical maturation inducer (positive control).

\section{Morphological characteristics of cells}

Morphological changes in cells were observed every day with the use of inverted optical phase contrast microscope. Cells were harvested on the 8-th and 11-th days, washed with PBS and centrifuged at $900 \mathrm{rpm}$ during 5 minutes. Cells were fixed with $2 \%$ glutaraldehyde for 2 hours at $4^{\circ} \mathrm{C}$ and washed twice with PBS. Then were stained with eosin azure according to Romanovsky-Giemsa. Light and phase contrast microscopy and cell photography were performed using the AxioVision 4 system (Carl Zeiss, Germany).

\section{Determination of DC immunophenotype}

The immunophenotype of DC was evaluated using flow cytometry on a Cytomix FC-500 (Beckman Coulter, USA) and Monoclonal 
Antibodies (mAbs) (eBiosciences, USA) marked with fluorochrome to a detectable molecules: CD11c-PE (3.9, Cat \# 12-0116 -42), CD11cPerCP (3.9, Cat \# 46-0116-42), CD34-FITC (4H11, Cat \# 11-034942), CD14-FITC (61D3, Cat \# 11-0149-42), CD86 FITC (BU63, Cat \# MHCD8601), CD83-FITC (HB-15e, Cat \# 11-0839-42), HLA-DRFITC (LN3, Cat \# 11-9956-42) (eBioscience, USA).

Cells were harvested after 8 and 11 days, washed with PBS and divided into several fractions of $5 \times 105$ cells $/ 100 \mu$ l. Each sample was measured three times. PE and FITC-tagged antibodies were added to the suspension to a final concentration of $5 \mu \mathrm{g} / \mathrm{ml}$ and incubated during 30 minutes at $4^{\circ} \mathrm{C}$ in the dark. Cells were washed twice with PBS and analyzed on a flow cytometer. FITC- tagged IgG isotypes were used as a control. Population of DCs and their subtypes was isolated using negative selection for linear markers CD3, CD14, CD19 and positive selection for markers MHCII, CD11c. Maturity of DC subtypes was evaluated by expression of surface markers on them - CD34, CD83, CD86, MHCII.

\section{Description of surface and endocytotic toll-like receptors (TLRs) of immunocompetent cells}

The content of TLRs-expressing DC was studied in vitro by flow cytometry with the use of mAbs: TLR2-FITC (CD282, TL2.1, Cat \# 11-9922-42, e-bioscience, USA), TLR3-PE (CD283, TLR3.7, Cat \# 12-9039- 82, e-bioscience, USA), TLR4-FITC (CD284, HTA, Cat \# MA1-22766, e-bioscience, USA), TLR8-FITC (CD288, Cat \# 395508, BioLegend, USA), TLR9-PE (CD289, Cat \# HM2087F-100UG, HycultBiotech, USA). Then they were detected on the Cytomix FC-500 flow cytometer (Beckman Coulter, USA) according to the procedure, described in the manufacturer's instructions.

\section{Statistical analysis}

Statistical analysis of data was carried out using the program "Statistica 10". The significance of differences between the compared values was determined using nonparametric basic statistics using the Mann-Whitney U-test. The differences were considered significant when $\mathrm{p} \leq 0.05$.

\section{Results}

\section{Morphological study}

After 3-4 hours bone marrow precursors of DCs adhered to coverslips placed in the wells of the culture plate. When cells were cultured during 24 hours in the presence of Recombinant Murine Granulocyte Macrophage Colony Stimulating Factor (rmGM-CSF) and interleukin-4 (rmIL-4), in addition to adherent cells, suspended cells were detected by phase contrast microscopy. After 72 hours the number and volume of adhered cells was increasing, and the formation of cell colonies was beginning.

On the 7-th day floating cells with dendritic protrusions appeared. On the 8-th day the suspended cells formed conglomerates, and the dendrites lengthened. After 72-hour incubation (11-th day of DC culture) with studied preparations, the colonies scattered, the cells acquired numerous heterogeneous processes and were evenly distributed in the medium.

\section{Analysis of the DC phenotype using flow cytometry}

On the 8-th day of incubation a moderate amount of CD11c+ cells $(75.8 \%)$ was detected in the cell culture from human bone marrow. The proportion of cells with expression of CD34 molecule, which is a marker of DC Immaturity (i-DC), was $31 \%$. The cell culture also contained a pool of monocytes expressing the CD11c/CD14+ marker (36.9\%). The content of cells with CD11c/MHC-II antigenic presentation molecules and CD11c/CD86 costimulatory molecules was low (13.36 and 6.2\%, respectively). In i-DC culture mature DCs - CD11c/CD83 - were found in trace amounts (5.5\%), among CD83/ CD86 double positive cells only $2.32 \%$ of them were found (Table 1 ).

On the 11-th day (3-rd day of cell cultivation in the presence of influenza vaccines and Polyoxidonium), immunophenotype of cells changed towards mature DCs. In cell cultures with vaccines Vaxigrip and Grippol plus the number of $\mathrm{CD} 11 \mathrm{c} / \mathrm{CD} 14$ positive cells decreased to $10.16 \%$ and $12.92 \%$, respectively. In the culture with Vaxigrip its amount was even lower compared to the classical inducer of TNF- $\alpha$ maturation (14.16\%, $\mathrm{p}>0.05)$. Compared with controls Polyoxidonium caused a decrease in the number of CD11c+/CD14+ cells (18.5\%), but compared with vaccines its activity was the lowest $(\mathrm{p}<0.05)$.

In stimulated cells the expression of immaturity marker CD34 decreased after incubation with Grippol plus vaccine (11.3\%). The results of CD34 expression in cultures with Vaxigrip and Polyoxidonium were comparable- $19.6 \%$ and $18.3 \%$, respectively. Moreover, TNF- $\alpha$ reduced the content of CD34+ DC by more than 4.8 times $(\mathrm{p}<0.01)$.

Under the influence of the studied drugs, an increase in the number of DCs with costimulating CD86 molecules was noted. The expression level of CD11c+/CD86+ increased significantly $(\mathrm{p}<0.05)$ under the influence of Vaxigrip (13.1\%) and Grippol plus (11.56\%) (2.11 And 2.34 times, respectively, compared with controls), but it was lower than that of the classical inducer TNF-a (18.8\%). Significant changes, but less pronounced, were noted during incubation with Polyoxidonium (9.78\%). A similar scene was observed in regard to the marker of terminal differentiation of DC - CD83: the activity of vaccines (Grippol plus, Vaxigrip) and Polyoxidonium was comparable, but lower than the activity of TNF- $\alpha$ in 1.97, 1.8 and 2.3 times, respectively $(\mathrm{p}<0.05)$.

Appropriately, as DCs mature, an activation marker-an antigenic molecule of MHCII-was exposed more intensively. Among CD11c+/ HLA-DR+ an increase in the number of DCs incubated with Vaxigrip was the most marked (32.4\% versus $13.36 \%$ i-DCs, $p<0.01)$. Two other drugs increased the number of activated cells: Grippol plus to $24.36 \%$, Polyoxidonium to $21.88 \%$. At the same time the results of both vaccines and adjuvant were lower than of the classical inducer of maturation TNF-a $(34.9 \%, \mathrm{p}<0.05)$.

Thus, addition of influenza vaccines into the culture of immature DCs induced the maturation of DCs, that evidenced by a decrease in the number of macrophage/monocyte pool, cells with expression of the low cell differentiation (cellular immaturity) CD34 molecules, and an increase in the level of cells expressing costimulatory CD11c/ CD86 molecules and CD83 terminal differentiation molecules.

Under the influence of Grippol plus and Vaxigrip an increase in number of TLR2-expressing cells was observed by 1.6 and 1.4 times respectively compared with $\mathrm{i}-\mathrm{DC}(\mathrm{p}<0.05)$. At the same time, the activity of classical maturation inducer was maximum (by 2.1 times 
Table 1: The effect of influenza vaccines on the immunophenotype of dendritic cells generated from human bone marrow.

\begin{tabular}{|c|c|c|c|c|c|}
\hline \multirow{2}{*}{ CD marker } & \multicolumn{5}{|c|}{ Number of cells (\%), M \pm SD, $\mathrm{Me}(\mathrm{Q} 1-\mathrm{Q} 3)$} \\
\hline & $\mathrm{i}-\mathrm{DC}$ * & TNF-a \# & Grippol plus & Vaxigrip $\alpha$ & Polyoxidonium $@$ \\
\hline CD11c & $\begin{array}{c}75.80 \pm 3.45 \\
75.3(74.8-77.6)\end{array}$ & $\begin{array}{c}76.90 \pm 3.67 \\
76(75-80)\end{array}$ & $\begin{array}{c}70.58 \pm 2.43 \\
70(69-72)\end{array}$ & $\begin{array}{c}70.48 \pm 2.28 \\
70.2(69.3-71)\end{array}$ & $\begin{array}{c}71.64 \pm 4.64 \\
72(67.1-75.3)\end{array}$ \\
\hline CD11c/CD14 & $\begin{array}{c}36.94 \pm 2.83 \\
37.6(34.7-38.4)^{\# x a @}\end{array}$ & $\begin{array}{c}14.16 \pm 2.06 \\
14.7(12.2-15.8)^{*}\end{array}$ & $\begin{array}{c}12.92 \pm 3.22 \\
11.3(10.7-15.5)^{*}\end{array}$ & $\begin{array}{c}10.16 \pm 2.9 \\
10.4(7.7-12.3)^{*}\end{array}$ & $\begin{array}{c}18.52 \pm 1.49 \\
18.2(17.3-19.6)^{* \# \alpha}\end{array}$ \\
\hline CD34 & $\begin{array}{c}31.0 \pm 3.17 \\
30.5(28.9-33.6)^{\# x a @}\end{array}$ & $\begin{array}{c}6.48 \pm 1.6 \\
6.5(5.8-7.8)^{+ \text {吅@ }}\end{array}$ & $\begin{array}{c}13.1 \pm 2.87 \\
13.7\left(12.2-15.4^{* \#+@}\right.\end{array}$ & $\begin{array}{c}19.66 \pm 2.28 \\
19.1(18-21)^{* @ \# n}\end{array}$ & $\begin{array}{c}18.36 \pm 3.01 \\
17(16.7-20)^{\circ}\end{array}$ \\
\hline CD11c/CD86 & $\begin{array}{c}6.2 \pm 1.3 \\
6.6(5.5-7.1)^{\# \mathrm{a} @}\end{array}$ & $\begin{array}{c}18.8 \pm 2 \\
18.9(18.5-20.3)^{*}\end{array}$ & $\begin{array}{c}11.56 \pm 1.87 \\
11.8(10.1-12.7)^{\star \#}\end{array}$ & $\begin{array}{c}13.1 \pm 2.8 \\
13.1(11.5-15.6)^{*}\end{array}$ & $\begin{array}{c}9.26 \pm 0.86 \\
9.5(8.9-9.6)^{\# \mathrm{n}}\end{array}$ \\
\hline CD11c/CD83 & $\begin{array}{c}5.5 \pm 1.3 \\
5.7(4.5-6.3)^{\# \alpha @ @}\end{array}$ & $\begin{array}{c}22.96 \pm 2.55 \\
23.8(21.1-24.4)^{*} \text { 吅 }\end{array}$ & $\begin{array}{c}11.64 \pm 1.49 \\
11.9(10.8-12.4)^{* \#}\end{array}$ & $\begin{array}{c}12.72 \pm 1.56 \\
12.6(11.7-13.8)^{\star \#}\end{array}$ & $\begin{array}{c}9.78 \pm 3.25 \\
9.9(7.3-12)^{* \#}\end{array}$ \\
\hline CD83/CD86 & $\begin{array}{c}2.32 \pm 0.95 \\
2.2(1.5-3.2)^{\# \alpha @ @ ~}\end{array}$ & $\begin{array}{c}12.84 \pm 2.11 \\
12.8(10.9-14.6)^{\mathrm{t}} @\end{array}$ & $\begin{array}{c}7.2 \pm 1.72 \\
6.9(6.2-7.8)^{\star \#}\end{array}$ & $\begin{array}{c}12.28 \pm 4.1 \\
14.5(8.4-15.2)^{\star}\end{array}$ & $\begin{array}{c}8.18 \pm 0.99 \\
8.5(7.4-8.8)^{\star \#}\end{array}$ \\
\hline CD11c/HLA-DR & $\begin{array}{c}13.36 \pm 1.93 \\
12.7(12.3-14.9)\end{array}$ & $\begin{array}{c}34.98 \pm 3.3 \\
35.3(33.7-36.7)\end{array}$ & $\begin{array}{c}24.36 \pm 3.1 \\
25.6(22.5-26)\end{array}$ & $\begin{array}{c}32.42 \pm 4.69 \\
32.8(28.9-36)\end{array}$ & $\begin{array}{c}21.88 \pm 1.58 \\
22(20.7-23.3)\end{array}$ \\
\hline
\end{tabular}

Notes: * $\#$, a, a, @ - p 0.05 - statistical significance of differences between compared groups (Mann-Whitney U-test).

Table 2: The effect of influenza vaccines on the expression of TLRs on dendritic cells generated from human bone marrow.

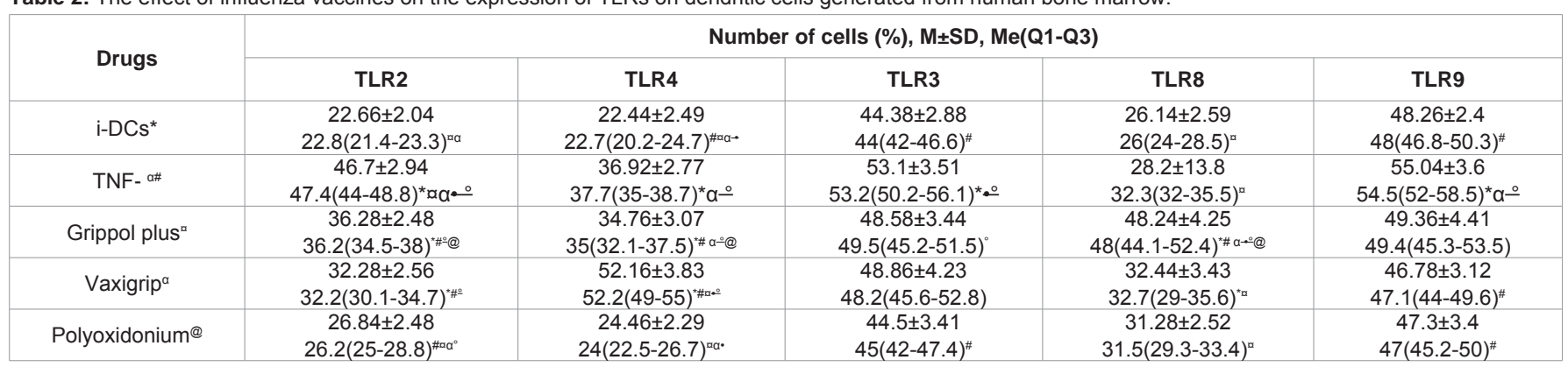

Notes: ${ }^{*}, \#, a, \alpha, \cdot,{ }^{\circ}, @-p<0.05$ - statistical significance of differences between compared groups (Mann-Whitney U-test).

higher) in comparison with i-DCs $(\mathrm{p}<0.05)$. Polyoxidonium had a negligible effect on the expression of this receptor, but in combination with influenza antigens in the Grippol plus vaccine the content of TLR2-expressing cells increased by 1.4 times $(\mathrm{p}<0.05)$ (Table 2$)$.

Vaxigrip had the maximum effect on increase of TLR4-positive DCs $(52.16 \%$, a 2.3 -fold increase compared to i-DCs and a 1.4 -fold increase compared to TNF- $\alpha, \mathrm{p}<0.05)$. The activity of Grippol plus was also significant (higher than i-DCs in 1.6 times, $\mathrm{p}<0.05$ ), but lower compared to Vaxigrip and classical maturation inducer TNF- $\alpha$. At the same time, Polyoxidonium, which is a part of Grippol plus, solely did not significantly affect the content of this type of cells.

With regard to TLR3, there were no significant differences in the effect of the studied drugs.

Grippol plus (48.24\%) had a significant effect on the content of TLR8-expressing cells compared with all the studied drugs, including Polyoxidonium itself $(31.28 \%$, an increase by 1.5 times, $\mathrm{p}<0.05)$. Under the influence of Vaxigrip the number of TLR8-expressing cells increased by 1.2 times (32.44\% versus $26.14 \%$ (i-DCs), $\mathrm{p}<0.05$ ).

All studied influenza vaccines did not significantly affect TLR9containing DCs, their levels were similar to each other and i-DCs. Only the classical inducer of maturation TNF- $\alpha$ contributed to a 1.1fold increase in the number of these cells compared to i-DC (55.04\% versus $48.26 \%$, $\mathrm{p}<0.05)$.

\section{Discussion}

On the 8-th day of culturing observation of immunophenotypic and morphological characteristics of cell types generated from human bone marrow precursors in the presence of GM-CSF and IL-4 revealed the formation of immature dendritic cells with CD34+ expression. Immature DCs can cause a state of "nonresponsiveness" of T-lymphocytes, inducing their anergy and apopotosis. In the absence of activating stimulus, immature DC are able to activate regulatory T-cells, leading to a limitation of the immune response or even to a state of "immunological silence". In the framework of implementation of the immune response to vaccination, it is extremely important to induce the maturation of DCs, since only mature DCs can trigger the activation of T-cells and stimulate their survival.

Combination of morphological, immunophenotypic and functional parameters determines the maturity of DCs [30,31]. In our study of DCs, cultured in the presence of influenza vaccines, that were tested as inducers of maturation, had typical morphological signs of mature cells: oval, often an irregular shape, with an eccentrically located nucleus, chromatin and numerous branching processes on the membrane, necessary for contact with surrounding cells [32]. Such intercellular contacts play an important role in presentation of antigens to T-lymphocytes.

Evaluation of the immunophenotype of DCs showed that studied influenza vaccines contributed to its maturation, since they led to decrease in the number of immature types with CD34+ marker. In particular, Vaxigrip and Polyoxdonium reduced its level by approximately 1.6 times, Grippol plus - by 2.4 times. In this context, it is interesting to compare the direct effect of Polyoxidonium itself and in combination with antigens in Grippol plus vaccine on maturation of DCs. Reducing the dose of antigen in the vaccine can be the risk of reduction of the immune response to the vaccine and lack of sufficient 
immunogenicity, and consequently, the subsequent poorer protective effect of vaccination.

That is why the observed effect of stimulation of DCs maturation under the influence of Polyoxidonium, which is used as an adjuvant in the influenza vaccine Grippol plus, explains the high level of effectiveness of the vaccine, that contains three times reduced $(5 \mu \mathrm{g})$ compared with standard $(15 \mu \mathrm{g})$ content of influenza virus antigens. Maturation of DCs is a necessary constituent of development of the immune response, plays an important role both in vaccination and in anti-infectious and antitumor protection [33-37] The effectiveness of Polyoxidonium as an adjuvant has been shown in a number of studies of other vaccines (for example, hepatitis A) [38] In addition, Polyoxidonium as an independent drug has shown to be effective in adjuvant therapy of cancer [39], as well as in the infectious disease [40-44]. In animal experiments, Polyoxidonium reduced mortality.

In this study the activity of Grippol plus - adjuvant containing vaccine - was significantly higher, therefore, we can assume that Polyoxidonium in its composition probably has an enhancing effect.

The key role in the process of antigenic presentation is played by costimulatory CD80/CD86 molecules that enhance contact between antigen-presenting cells and T-lymphocytes [45]. It is known, in the absence of sufficient co-stimulation, T-lymphocytes undergo apoptosis after contact with DCs.

The number of dendritic cells with co-stimulating CD11c/CD86 molecules practically did not increase after addition of Polyoxidonium into the culture, while in samples with vaccines an increase of CD11c/ CD86 expression was observed, that is also one of indicators of DCs maturation.

The CD83 molecule on DCs is an indicator of their terminal differentiation and maturity. Expression of CD83 in population of DCs without maturation inducer (i-DC) was only $5.5 \%$, while addition of the studied vaccines increased the number of mature cells by almost 2 times, in culture with Vaxigrip it was maximum (2.3fold increase). Polyoxidonium did not show such significant effect as Grippol plus (1.5-fold and 2-fold increase, respectively). The number of double positive CD83/CD86 cells was more influenced by Vaxigrip $(12.3 \%)$, the equal values were in culture with classical maturation inducer $(12.8 \%, \mathrm{p}<0.05)$. Similar data were previously obtained in animal experiments [46].

In immunological defense, recognition process play a key role, since heterogenous antigens can be presented and eliminated only if they are selected by specific receptors of innate immunity. These are the Pattern Recognition Receptors (PRRs) that transmit activation signals, resulting in the release of cytokine cascade by immune cells [47-49]. PRRs include Toll-Like Receptors (TLRs) that recognize Pathogen-Associated Molecular Structures (PAMPs) presented both on microbial cells and on their components (antigens, vaccines) $[50,51]$.

In our study the activity of Grippol plus and Vaxigrip was high, as they induced an increase in the pool of TLR2, TLR4, TLR8 positive DCs. Grippol plus more actively induced differentiation of TLR2 and TLR8 expressing DCs, while Vaxigrip - TLR4 and TLR8. Polyoxidonium in the studied concentration did not significantly affect the content of TLR-expressing cells, although in combination with Grippol plus it must be assumed that it had an adjuvant effect.

\section{Conclusion}

This study has demonstrated the possibility of obtaining dendritic cells from human bone marrow with cytokine stimulation and using it as a model for examination of ability to induce DCs maturation by influenza vaccines in vitro. In the future it can serve as a criterion for evaluating the effectiveness of developing vaccines.

\section{References}

1. Patente TA, Pinho MP, Oliveira AA, Evangelista GCM, Bergami-Santos PC, Barbuto JAM. Human Dendritic Cells: Their Heterogeneity and Clinical Application Potential in Cancer Immunotherapy. Front Immunol. 2018; 9: 3176.

2. Wang W, Li J, Wu K, Azhati B, Rexiati M. Culture and Identification of Mouse Bone Marrow-Derived Dendritic Cells and Their Capability to Induce T Lymphocyte Proliferation. Med Sci Monit. 2016; 22: 244-250.

3. Wang $\mathrm{HL}, \mathrm{Xu} \mathrm{H}, \mathrm{Lu} \mathrm{WH}$, et al. In vitro and in vivo evaluations of human papillomavirus type 16 (HPV16)-derived peptide-loaded dendritic cells (DCs) with a CpG oligodeoxynucleotide (CpG-ODN) adjuvant as tumor vaccines for immunotherapy of cervical cancer. Arch Gynecol Obstet. 2014; 289: 155-162.

4. Rosalia RA, Cruz LJ, van Duikeren S, et al. CD40-targeted dendritic cell delivery of PLGA-nanoparticle vaccines induce potent anti-tumor responses. Biomaterials. 2015; 40: 88-97.

5. Jiang PL, Lin HJ, Wang HW, et al. Galactosylated liposome as a dendritic cell-targeted mucosal vaccine for inducing protective anti-tumor immunity. Acta Biomater. 2015; 11: 356-367.

6. Lin $\mathrm{W}$, Chen $\mathrm{YL}$, Jiang L, Chen JK. Reduced expression of chemerin is associated with a poor prognosis and a lowed infiltration of both dendritic cells and natural killer cells in human hepatocellular carcinoma. Clin Lab. 2011; 57: 879-885.

7. Zheng C, Yu G, Wang H, et al. Meta-analysis of chemotherapy and dendritic cells with cytokine-induced killer cells in the treatment of non-small-cell lung cancer. Int J Clin Exp Med. 2015; 8: 14527-14537.

8. Sabado RL, Balan S, Bhardwaj N. Dendritic cell-based immunotherapy. Cell Res. 2017; 27: 74-95

9. Chen $P$, Liu X, Sun Y, Zhou P, Wang Y, Zhang Y. Dendritic cell targeted vaccines: Recent progresses and challenges. Hum Vaccin Immunother. 2016; 12: 612-622.

10. Rosalia RA, Cruz LJ, van Duikeren S, et al. CD40-targeted dendritic cell delivery of PLGA-nanoparticle vaccines induce potent anti-tumor responses. Biomaterials. 2015; 40: 88-97.

11. Jiang PL, Lin HJ, Wang HW, et al. Galactosylated liposome as a dendritic cell-targeted mucosal vaccine for inducing protective anti-tumor immunity. Acta Biomater. 2015; 11: 356-367.

12. Llopiz D, Ruiz M, Silva L, Sarobe P. Enhancement of Antitumor Vaccination by Targeting Dendritic Cell-Related IL-10. Front Immunol. 2018; 9:1923.

13. Li Z, Ju X, Silveira PA, Abadir E, Hsu WH, Hart DNJ, et al. CD83: Activation Marker for Antigen Presenting Cells and Its Therapeutic Potential. Front Immunol. 2019; 10: 1312.

14. Dyakonova VA, Dambaeva SV, Pinegin BV, Khaitov RM. Study of interaction between the polyoxidonium immunomodulator and the human immune system cells. Int Immunopharmacol. 2004; 4: 1615-1623.

15. Kostinov MP, Cherdantsev AP, Savisko AA, Tarbaeva DA, Slovyova IL. True and false reactions in pregnant women to introduction of influenza vaccine. Gynaecology, obstetrics and perinatology. 2011; 10: 44-48.

16. Chebykina AV, Kostinov MP, Magarshak OO. Estimation of Safety and Efficiency of Vaccination from a Flu at Patients with Chronic Obstructive Lung Syndrome. Epidemiology and Vaccinal Prevention. 2010; 6: 5053

17. Protasov AD, Ryzhov AA, Zhestkov AV, Kostinov MP. The influence of comlex 
vaccination against pneumococcus, haemophilus influenzae type $B$ infections and influenza in the clinical course of chronic obstructive pulmonary disease. The bulletin of contemporary clinical medicine. 2011; 4: 80-84.

18. Vaccination of adults with bronchopulmonary pathology. Guideline for doctors. Ed. M.P. Kostinov. Moscow: Art Studio "Sozvezdie", 2013.

19. 19. Vaccination of children with weak health. Practical manual for doctors. 4 th edition. Ed. M.P.Kostinov. Moscow: «Medicine for everybody». 2013.

20. Guidance for Clinical Immunology in Respiratory Medicine. 1st edition. Eds. M.P. Kostinov, A.G. Chuchalin. Moscow: LLC «ATMO»: 2016 (in Russ.)

21. Tarasova AA, Kolbasina EV, Lukushkina EF, Kuzmichev Yu.G., Kostinov MP. Immunogenicity and Safety of a Trivalent Subunit Immunoadjuvant Influenza Vaccine in Children with Type 1 Diabetes: Results of a Prospective Comparative Study. Current Pediatrics. 2016; 15: 487-497.

22. Respiratory medicine. Guidelines. 2nd edition, revised and enlarged Eds. A.G. Chuchalin. Volume 2. Section 9. Respiratory infections. 9.10. Vaccination 2017: 173-183.

23. Cherdantsev AP, Kuselman Al, Sinitsyna MN, Shalyagina ME, Kostinov MP, Tarbaeva DA. Study of the clinical safety of vaccination against influenza in pregnant women. Medical Almanac. 2011; 4: 120-122.

24. Vaccine prevention of influenza in pregnant women. Guidelines for doctors Eds. A. P. Cherdantsev, M.P. Kostinov, A.I. Kuselman. Moscow: 4Mpress, 2013.

25. Zverev VV, Kostinov MP, Cherdantsev AP, Kuselman Al, Kiselev OI, Erofeeva MK, et al. Vaccination against influenza in pregnancy. Federal clinical guidelines. Remedium. 2015; 42.

26. Kostinov MP, Cherdantsev AP, Praulova DA, Kostinova AM, Polishchuk VB Analysis of safety for fetus of immunoadjuvant influenza vaccines in pregnant women. Pediatria. Journal named after G.N. Speransky. 2017; 96: 91-96.

27. Kostinov MP, Cherdantsev AP, Akhmatova NK, Praulova DA, Kostinova AM, Akhmatova EA, et al. Immunogenicity and safety of subunit influenza vaccines in pregnant women. ERJ Open research.- 2018 .4: 00060-2017.

28. Gynecology. National Guideline. 2-nd Edition. Eds. Savelyeva GM, Sukhikh GT, Serov VN, Manukhin IB, Radzinsky VE. Moscow: GEOTAR-Media, 2017.

29. Boytsov SA, Loukianov MM, Platonova EV, Gorbunov VM, Romanchuk SW, Nazarova OA, et al. Efficiency of influenza vaccination in patients with circulatory system diseases under dispensary observation in outpatient clinics: prospective follow-up monitoring data. Rational Pharmacotherapy in Cardiology. 2016; 12: 703-710.

30. Dalod M, Chelbi R, Malissen B, Lawrence T. Dendritic cell maturation: functional specialization through signaling specificity and transcriptional programming. EMBO J. 2014; 33: 1104-1116.

31. Schlitzer A, Zhang W, Song M, Ma X. Recent advances in understanding dendritic cell development, classification, and phenotype. F1000Res. 2018; 7:F1000.

32. Schraml BU, Reis e Sousa C. Defining dendritic cells. Curr Opin Immunol. 2015; 32: 13-20

33. Sokolova TM, Poloskov VV, Shuvalov AN. The vaccines "Grippol" and "Vaxigrip" are activators of gene expression of innate immunity system in the cells of acute monocytic leukemia THP1. Eurasian Union of Scientists 2016; 5: 61-63.

34. Sokolova TM, Shuvalov AN, Poloskov VV, Shapoval IM, Kostinov MP. Grippol, Vaxigrip and Influvac vaccines - inductors of innate and adaptive immunity factor genes in human blood cells. Journal of Microbiology, Epidemiology and Immunobiology. 2014; 5: 37-43.

35. Sokolova TM, Shuvalov AN, Poloskov VV, Shapoval IM, Kostinov MP.
Simulation of signaling receptors gene expression and induction of synthesis of cytokines in human blood cells by drug Ribonucleat sodium and its combination with inactivated influenza vaccines. Molecular medicine. 2015; 1: $12-17$

36. Kostinov MP, Akhmatova NK, Khromova EA, Skhodova SA, Stolpnikova VN, Cherdantsev AP et al. The impact of adjuvanted and non-adjuvanted influenza vaccines on the innate and adaptive immunity effectors. IntechOpen book series. Infectious diseases, volume 1. Influenza. Therapeutics and challenges. Edited by Shailendra K. Saxena.2018. 5: 83-109.

37. Chromova EA, Akhmatova EA, Skhodova SA, Semochkin IA, Khomenkov VG, Akhmatova NK, et al. Effect of influenza vaccines on subpopulations of blood dendritic cells. Journal of microbiology epidemiology immunobiology. 2016; 5: 23-28.

38. Immunomodulators and vaccination. Red. M.P.Kostinov, I.L.Soloviova. M. 4Mpress, 2013: 272

39. Alexia C, Cren M, Louis-Plence P, Vo D-N, El Ahmadi Y, Dufourcq-Lopez E, et al. Polyoxidonium $®$ Activates Cytotoxic Lymphocyte Responses Through Dendritic Cell Maturation: Clinical Effects in Breast Cancer. Front. Immunol. 2019; 10: 2693.

40. A practical guide for doctors. M.P. Kostinov, ed. M .: Medicine for all, 1997: 111.

41. Mavzyutova GA, Mukhamadieva LR, Fazlyeva RM, Mirsaeva GKh, Tyurina EB. Rational immunocorrection in treatment of community-acquired pneumonia // Medical Council. 2015; 16: 68-73.

42. Averkiev VL, Tarasenko VS, Latysheva TV, Averkieva LV. Correction of immunological disorders in patients with pancreatic necrosis // Immunology. 2002; 23: 359-363

43. Luss LV. The role and place of immunomodulating therapy in treatment of infectious and inflammatory diseases occurring on the background of secondary immune deficiency // Medical Council. 2013; 11:78 - 80.

44. Korovkina ES, Kostinov MP. Immune mechanisms of communityacquired pneumonia and copd due to infectious etiology and methods of immunotherapy. Journal of microbiology, epidemiology and immunobiology. 2019; 2:100-109.

45. Paul WE. Fundamental Immunology, 6th edition. Philadelphia: Wolters Kluwer/ Lippincott Williams \& Wilkins, 2008; 1603.

46. Talayev VYu, Matveichev AV, Zaichenko IE, Talaeyva MV, Babaykina ON, Voronina EV Polyoxidonium ${ }^{\circledR}$ vaccine adjuvant enhances the immune response to low dose of influenza antigens. Scientific support of anti-epidemic protection of the population: current problems and solutions. In the collection of scientific works of the All-Russian Scientific and Practical Conference with international participation dedicated to the 100th anniversary of Blokhina Scientific Research Institute of Epidemiology and Microbiology of Nizhny Novgorod, Rospotrebnadzor. Nizhny Novgorod. 2019: 363-365.

47. Kawai T, Akira S. The role of pattern-recognition receptors in innate immunity update on Toll-like receptors // Nature Immunology. 2010, 11: 373-384.

48. Iwasaki A, Pillai PS. Innate immunity to influenza virus infection. Nat Rev Immunol. 2014; 14: 315-328.

49. Chow J, Franz KM, Kagan JC. PRRs are watching you: Localization of innate sensing and signaling regulators. Virology. 2015; 479-480: 104-109.

50. Dowling JK, Mansell A. Toll-like receptors: the swiss army knife of immunity and vaccine development. // Clin TransI Immunology, 2016; 5: e85.

51. Vijay K. Toll-like receptors in immunity and inflammatory diseases: Past, present, and future. Int Immunopharmacol. 2018; 59: 391-412. 